\title{
Cost-Effectiveness of Bridging Anticoagulation
}

\author{
Matthew A. Pappas, MD, MPH ${ }^{1,2,3}$ \\ Check for \\ updates \\ ${ }^{1}$ Cleveland Clinic Lerner College of Medicine, The Cleveland Clinic Foundation, Cleveland, OH, USA; ${ }^{2}$ Center for Value-Based Care Research, The \\ Cleveland Clinic Foundation, Cleveland, OH, USA; ${ }^{3}$ Department of Hospital Medicine, The Cleveland Clinic Foundation, Cleveland, OH, USA.
}

J Gen Intern Med 36(1):226

DOI: $10.1007 / \mathrm{s} 11606-019-05322-\mathrm{x}$

(c) Society of General Internal Medicine 2019

$\mathrm{T}_{\mathrm{w}}$ o the Editor

We thank Dr. Rose for his interest in our article, and for his comments here. We agree that no trial has demonstrated benefit of bridging, and that no observational studies have shown clear reduction in thromboembolism. As discussed in this article and elsewhere, the key assumption and limitation of our analysis is that heparin products reduce the risk of arterial thromboembolism. ${ }^{1,2}$ If heparin products are not effective at reducing risk of thromboembolism (or arterial thromboembolism specifically), bridging should be rejected entirely, and many other current uses of heparin products should be discarded as well.

Even if heparin products are effective, we agree that bridging should be avoided for nearly all patients, and potentially only prescribed for a selected subset. As a rough estimate, the subgroups that appear to receive cost-effective benefit in our analysis comprised around $0.5 \%$ of one real-world cohort (3.1\% when using a higher cost-per-QALY threshold). ${ }^{3}$ To a first approximation, no patients should receive bridging of the sort we have considered. If bridging is to be used, it should be used an order of magnitude less frequently than the $24 \%$ observed in registry data. ${ }^{4}$

Our analysis also demonstrates that if bridging is to be used, selection by both bleeding risk and stroke risk is essential. Although the risk scores we used are highly imperfect, HASBLED has some demonstrated prognostic value in the perioperative period, and both are incorporated into expert consensus recommendations for bridging. ${ }^{5,6}$ If the practice is to be used, stratification by both bleeding risk and stroke risk is essential, and we know of no better methods of risk stratification here.

In light of the small population of interest and difficulty enrolling patients at high risk of stroke in the largest trial of bridging, ${ }^{7}$ we regard it as unlikely that a sufficiently powered, high-quality trial will be performed in the population of interest in the near future. But bridging persists, and we think it unlikely that clinicians will stop bridging entirely. ${ }^{8}$ With our analysis, we hope to guide the practice toward a more thoughtful integration of imperfect evidence.

Corresponding Author: Matthew A. Pappas, MD, MPH; Cleveland Clinic Lerner College of Medicine, The Cleveland Clinic Foundation, Cleveland, OH, USA (e-mail: pappasm@ccf.org).

\section{Compliance with ethical standards:}

Conflict of Interest: Dr. Pappas has no conflicts to disclose.

\section{REFERENCES}

1. Pappas MA, Barnes GD, Vijan S. Cost-Effectiveness of Bridging Anticoagulation Among Patients with Nonvalvular Atrial Fibrillation. J Gen Intern Med. 2019;34(4):583-590. https://doi.org/10.1007/s11606018-4796-9

2. Pappas MA, Barnes GD, Vijan S. Personalizing Bridging Anticoagulation in Patients with Nonvalvular Atrial Fibrillation-a Microsimulation Analysis. J Gen Intern Med. 2017;32(4): 464-470. https://doi.org/10.1007/ s11606-016-3932-7

3. Marcucci M, Lip GYH, Nieuwlaat R, Pisters R, Crijns HJGM, Iorio A. Stroke and bleeding risk co-distribution in real-world patients with atrial fibrillation: the Euro Heart Survey. Am J Med. 2014;127(10):979-986.e2. https://doi.org/10.1016/j.amjmed.2014.05.003

4. Steinberg BA, Peterson ED, Kim S, et al. Use and outcomes associated wisth bridging during anticoagulation interruptions in patients with atrial fibrillation: findings from the Outcomes Registry for Better Informed Treatment of Atrial Fibrillation (ORBIT-AF). Circulation. 2015;131(5):488494. https://doi.org/10.1161/CIRCULATIONAHA.114.011777

5. Omran H, Bauersachs R, Rübenacker S, Goss F, Hammerstingl C. The HAS-BLED score predicts bleedings during bridging of chronic oral anticoagulation. Thromb Haemost. 2012. https://doi.org/10.1160/th1112-0827

6. Periprocedural Management of Anticoagulation Writing Committee JU, Doherty JU, Gluckman TJ, et al. 2017 ACC Expert Consensus Decision Pathway for Periprocedural Management of Anticoagulation in Patients With Nonvalvular Atrial Fibrillation: A Report of the American College of Cardiology Clinical Expert Consensus Document Task Force. J Am Coll Cardiol. 2017. https://doi.org/10.1016/j.jacc.2016.11.024

7. Douketis JD, Spyropoulos AC, Kaatz S, et al. Perioperative Bridging Anticoagulation in Patients with Atrial Fibrillation. N Engl J Med. 2015;373(9):823-833. https://doi.org/10.1056/NEJMoa1501035

8. Feinstein AR. The "chagrin factor" and qualitative decision analysis. Arch Intern Med. 1985;145(7):1257-1259. http://www.ncbi.nlm.nih.gov/ pubmed/4015276. Accessed 23 July 2019.

Publisher's Note Springer Nature remains neutral with regard to jurisdictional claims in published maps and institutional affiliations. 